\title{
ENGAJAMENTO, PLANEJAMENTO E EXPERIÊNCIAS DE VIAGEM COMPARTILHADAS NAS REDES SOCIAIS
}

\section{ENGAGEMENT, PLANNING AND TRAVEL EXPERIENCES SHARED ON SOCIAL NETWORKS}

\section{COMPROMISO, PLANIFICACIÓN Y EXPERIENCIAS DE VIAJE COMPARTIDA EN REDES SOCIALES}

\author{
Fabricia Duriuex Zucco ${ }^{1}$ \\ Giselle Bahr ${ }^{2}$ \\ Pablo Flôres Limberger ${ }^{3}$
}

Resumo: As redes sociais são, na atualidade, uma das principais ferramentas de promoção do turismo, no Brasil. A proposta desse artigo é analisar o engajamento, o planejamento e as experiências de viagens, compartilhadas nas redes sociais virtuais. Realizou-se uma pesquisa quantitativa que utiliza, como procedimentos técnicos, a revisão bibliográfica, a pesquisa de survey com a escala Likert de sete pontos. Inicialmente, para o compartilhamento de experiências de viagens online, as dimensões compreendidas foram formadas de acordo com a teoria de Jacobsen e Munar (2014) e, para o planejamento de viagens, com as de Parra-López et al (2011). Com a finalidade de obter maior compreensão do modelo, foi realizada uma análise de modelagem equacional e uma análise fatorial. A coleta de dados, desse objeto de pesquisa, realizou-se no ambiente online, por meio de um questionário de preenchimento automático. Esse trabalho contribui para a avaliação das características de engajamento, de planejamento e das experiências de viagens compartilhadas nas redes sociais virtuais, e revela que os fatores; utilitário, planejamento e social têm forte relação com o compartilhamento, no qual o fator "utilitário" é o preponderante.

Palavras-chave: Redes Sociais Virtuais. Engajamento. Planejamento. Compartilhamento. Viagens.
Abstract: Social networks are currently one of the main tools to promote tourism in Brazil. The purpose of this article is to analyze the engagement, planning and travel experiences shared in online social networks. A quantitative research was carried out using as technical procedures the bibliographical review and a survey with a seven-point Likert scale. Initially, for the sharing of online travel experiences, the dimensions were formed according to the theory of Jacobsen and Munar (2014) and, for the planning of trips, with those of Parra-López et al (2011). In order to obtain a better understanding of the model, an

\footnotetext{
${ }^{1}$ Doutora em Administração. Professora do programa de mestrado e doutorado em turismo da Univali. Professora do depto de comunicação da Furb. fabricia@furb.br

${ }^{2}$ MBA em Branding na Universidade do Vale do Itajaí. Bacharel em publicidade e propaganda

${ }^{3}$ Doutor em Turismo e Hotelaria pela Universidade do Vale do Itajaí. Professor e pesquisador no programa de mestrado e doutorado em turismo e hotelaria da Universidade do Vale do Itajaí. pablofl@univali.br
} 
equational modeling analysis and a factorial analysis were performed. Data collection was performed in the online environment, through an auto-complete questionnaire. This work contributes to the evaluation of the characteristics of engagement, planning and shared travel experiences in virtual social networks and reveals that the utilitarian, planning and social factors are strongly related to sharing, in which the "utility" factor is the preponderant.

Keywords: Virtual Social Networks. Engagement. Planning. Sharing. Travels.

Resumen: Las redes sociales son, en la actualidad, una de las principales herramientas de promoción de turismo en Brasil. El propósito de este artículo es analizar el compromiso, la planificación y experiencias de viajes compartidos en redes sociales virtuales. Se realizó una investigación cuantitativa que utiliza como procedimientos técnicos, la revisión de la literatura y una investigación de la encuesta con la escala de Likert de siete puntos. Inicialmente, para el intercambio de experiencias de viajes en línea, dimensiones se formaron de acuerdo con la teoría Munar y Jacobsen (2014), y planificación de viajes, con López-Parra et al (2011). Con el fin de lograr una mayor comprensión del modelo, se llevó a cabo un análisis de modelado ecuacional y un análisis de factor. Para la recolección de datos se llevó a cabo en el ambiente en línea, a través de un cuestionario de autocompletar. Este trabajo contribuye a la evaluación de las características de compromiso, planificación y la experiencia de viaje compartido en redes sociales virtuales y revela que los factores: utilidad, la planificación y social tienen una fuerte relación con el intercambio, en el que el factor de la "utilidad" es predominante.

Palabras clave: redes sociales virtuales. Compromiso. Planificación. Compartiendo. Los viajes

\section{Introdução}

Na primeira década do século 21, novas tecnologias de mídia e redes sociais virtuais, como Facebook, Twitter, Instagram e Youtube, começaram a transformar as práticas sociais, políticas e de informação dos indivíduos. As teias de interações, entre usuários de serviços online, comunidades, corporações, governos e outras instituições, ganharam amplitude por meio de conflitantes motivos e de diversos interesses.

Ocorreram profundas mudanças na sociedade, decorrentes das tecnologias, e as plataformas digitais fomentaram, em tempo real, uma explosão de conteúdos e soluções instantâneas. Devido a essas mudanças, a web passou de uma situação de mera fonte de leitura para uma de participação mais efetiva, de uma situação estática, para uma dinâmica e, atualmente, de uma situação de reação para uma de engajamento (Gabriel, 2010). A 
interatividade da internet proporcionou mudanças significativas na maneira das pessoas e das empresas se relacionarem.

Atualmente, as redes sociais virtuais são utilizadas, pela sociedade, para o compartilhamento de experiências, de informações e de conhecimentos, mediante a união de propósitos afins. Elas criam bases e informações relevantes para o setor em que atuam. Anteriormente, o que existia eram as experiências particulares, compartilhadas apenas entre os mesmos círculos de contatos. Essas experiêmcias foram expostas em bases globais de informações, com a possibilidade de serem analisadas por empresas e organizações, como por exemplo, as de turismos e, assim puderam contribuír socialmente (Jacobsen \& Munar, 2014).

As redes sociais virtuais têm realizado uma importante e significativa mudança no setor turístico. A facilidade de trocas de informações pela internet, a possibilidade de compra de passagens e de diárias de hospedagem, são de grande auxílio para que os usuários, com essa autonomia, possam fazer as suas próprias escolhas e pesquisar as opiniões de outros turistas, publicadas na internet (Leung et al., 2013; Jacobsen \& Munar, 2014; Cabiddu et al, 2014; Wang et al 2016; Yoo \& Gretzel, 2016).

O advento das tecnologias de mídia social permitiu aos turistas o compartilhamento de suas experiências de viagem. Essas experiências compartilhadas são reconhecidas como uma importante fonte de informação para outros turistas e também como possíveis influenciadoras de viajantes, na tomada de decisão sobre a sua viagem. $\mathrm{O}$ engajamento da mídia social mudou, radicalmente, a maneira dos indivíduos realizarem as suas viagens (Zeng \& Gerritsen, 2014). Destaca-se a importância da mídia social, como fonte de informação para organização de viagens. Esse assunto foi abordado em diversos estudos pelos seguintes autores: Arsal (2008), Law (2014), Ip, Lee e Law (2012), Kang e Schuett (2013), Jacobsen e Munar (2014); Bilgihan, et al. (2016).

O conceito de engajamento trata do envolvimento cognitivo e emocional do internauta, e compreende diferentes níveis de interação experimentada, dentre eles: a atenção, a absorção, o compartilhamento, a aprendizagem e a defesa. Nos últimos anos, foram realizados importantes estudos acerca do engajamento do consumidor, especialmente, no setor turístico (Kumar et al., 2010; Cheung, 2011; Hollebeek et al., 2014; Vivek et al., 2014; So et al 2016; Wang et al., 2016). 
O presente estudo contribui para a compreensão da utilização das redes sociais virtuais, no que se refere à escolha do destino das viagens a lazer e, tem, por objetivo, analisar as relações entre o engajamento, o planejamento e as experiências de viagens, compartilhadas nas redes sociais virtuais.

Estruturalmente, o trabalho está organizado da seguinte forma: a fundamentação teórica sobre o engajamento, o planejamento e o compartilhamento nas redes sociais; os procedimentos metodológicos; os resultados da pesquisa; e, por fim, a apresentação das considerações finais.

\section{Engajamento, planejamento e compartilhamento nas redes sociais.}

O engajamento pressupõe a análise dos componentes cognitivos e afetivos dos usuários de um site, visto que as marcas interagem com diferentes tipos de clientes e buscam constantemente se destacar diante dos concorrentes (Browden, 2009).

Desde sua perspectiva publicitária, as principais características do engajamento contemplam: conhecer as individualidades de cada consumidor, produzir fidelidade à marca, conquistar a confiança e promover compartilhamento de experiências entre marca e usuários. Para Brodie (2013), dentre as principais consequências do engajamento estão: a lealdade, a satisfação, os direitos dos consumidores, a conexão e união emocional, a confiança e, o compromisso dos consumidores com as marcas.

Quando o consumidor está profundamente vinculado aos produtos de uma determinada marca, ele não só faz uso deles, mas, também, volta a os adquirir. Ele interage com a marca e, por meio de pronunciamentos públicos, explica como o produto mudou a sua vida (Chamusca, 2011). Sterne (2000) complementa e defende que as marcas precisam criar esse ambiente de interatividade entre os consumidores, para que se conheçam, tornem públicas as suas queixas da marca do produto e, assim, sejam capazes de se ajudarem mutuamente.

$\mathrm{O}$ engajamento sugere um interesse dos consumidores na participação de atividades conjuntas, que os vincule à comunidade virtual, e no aumento do valor das marcas para si e para os outros (Wirtz, 2013). O engajamento ultrapassa as barreiras do processo de decisão de compra, caminha, lado a lado, com a satisfação, e faz com que fãs, seguidores ou consumidores de uma 
marca, não apenas consumam, mas também, exponham, para suas redes de contato, suas motivações e desejos (Hollebeek et al., 2014; Vivek et al., 2014; Wang et al., 2016).

Wang e Fesenmaier (2004) realizaram um estudo sobre as características dos usuários que utilizam a internet em busca de informações sobre as viagens turísticas, e identificaram que eles, no meio online, buscam e compartilham informações que atendam às suas necessidades funcionais e sociais.

A busca do engajamento passa a ser fator crítico no cenário digital atual. Obriga a ações contínuas de relacionamento que têm, por objetivo, a conquista e a conversão do público em relação à marca. Para que as ações de engajamento sejam efetivas, é necessário o conhecimento profundo dos públicos que se relacionam com a marca. A cada interação realizada, torna-se essencial a realização de mapeamentos sociais e, em consequência, se fazer avanços no grau do relacionamento (Gabriel, 2010).

O engajamento do consumidor, em uma comunidade de marca virtual, envolve experiências ativas entre os consumidores e as marcas, e/ou entre os outros membros da comunidade. O consumidor engajado é dependente, e apresenta um estado psicológico caracterizado por níveis de intensidade flutuantes, que ocorrem com a dinâmica, a interatividade e o engajamento nos processos. "Consumidor" é um conceito multidimensional que inclui o cognitivo, o emocional e/ou as dimensões comportamentais, e desempenha um papel central no processo de troca e, por consequência, nos processos de engajamento com interatividade na comunidade de marca digital (Brodie, 2013; Wang et al 2016).

O internauta pode estar envolvido com o site, visitá-lo com frequência, acompanhar as notícias do dia, mas não ser engajado. A participação, por si só, não garante pessoas engajadas. Cabe aos estudos, verificarem o limite entre participação e engajamento. É importante entender os motivos pelos quais as pessoas participam das ações nos ambientes digitais. Faz-se necessária a compreensão dessa dinâmica, para que as organizações tenham dados mais efetivos sobre o engajamento (Haven, 2007).

Atualmente, as redes sociais representam uma das principais ferramentas de promoção do turismo no Brasil. São essenciais, tanto na divulgação, quanto na fomentação, do setor pelo país. (Brasil, MTur, 2015). De acordo com Seegers e Vermeulen (2009), muitos consumidores 
realizam suas consultas online antes de planejarem e organizarem suas viagens. No entanto, pouco se sabe sobre qual o impacto dessas consultas nas tomadas de decisão desses consumidores. Bennett e Lai (2005) defendem que a internet tem mudado a maneira das organizações conduzirem os seus negócios e também repercutem na cadeia de distribuição do turismo.

Standing (2004) argumenta que os ambientes tecnológicos desafiam os consultores de viagens nas vendas dos pacotes turísticos. A introdução da internet gerou um debate sobre qual seria o futuro das agências de viagem, como agentes intermediários entre os principais fornecedores e os viajantes, e se, essa função, não estaria sendo eliminada com a criação das redes sociais e do ambiente virtual. Todos esses acontecimentos têm transformado e remodelado o formato de distribuição de viagens.

De acordo com Bennett e Lai (2005), para que as agências de viagens permaneçam competitivas, é necessário que se reposicionem diante do impacto que têm recebido das novas tecnologias virtuais, como por exemplo, os serviços de viagens e-commerce.

Existe um número crescente de viajantes conectados, ou que utilizaram seus smartphones no planejamento de suas viagens. Ter acesso a esse tipo de viajante seria uma grande oportunidade para as empresas. Na atualidade, uma quantidade cada vez maior de pessoas planeja e reserva suas viagens pelo celular, e seus smartphones são companheiros essenciais. O número de viajantes, que realizaram suas reservas por meio dos aplicativos móveis, dobrou de 2014 para 2015 e a reserva da hospedagem se tornou mais habitual (TripAdvisor Insights, 2015).

Calder, Malthouse e Schaedel (2009) defendem que as pessoas também utilizam a web para facilitar a sua interação com outras pessoas. Elas afirmam que a navegação por um site melhora a sua autoestima e que experimentam uma sensação de prazer intrínseco em utilizar o site, por si só. Valorizam a entrada de novos usuários e se sentem motivadas com a entrada em uma comunidade virtual, pois, por meio dessa participação, é criada uma sociabilização, que gera um envolvimento social interativo, como principal característica.

Especificamente no campo do turismo, as redes sociais representam uma ferramenta de extrema importância para o sucesso dos negócios no setor. É um ambiente muito propício para estabelecer boas relações com os clientes. De acordo com, Hays, Page e Buhalis (2012), essas 
ferramentas estão mudando a maneira da sociedade consumir, e, ao mesmo tempo, contribuempara a criação de informação.

Parra-López et al (2010) desenvolveram um estudo que identificou doze dimensões para a compreensão do comportamento dos usuários que planejam suas viagens, a partir do uso da mídia social. São elas: funcional; psicológica e hedônica; social; esforço; privacidade; dificuldade; acesso; ambiente; predisposição; confiança; e intenções de uso.

As redes sociais se tornaram a maneira mais popular de comunicação entre viajantes, amigos e familiares, sendo também importantes no momento de decisão do destino de viagem. Para Xiang e Gretzel (2010), os departamentos de marketing não podem mais ignorar o papel que a mídia social exerce na distribuição da informação relacionada a viagens.

\section{Procedimentos metodológicos}

Nesse estudo empírico, foram utilizados métodos quantitativos que têm como função a quantificação dos resultados, ou seja, por meio de análises estatísticas é possível obter os dados coletados em soluções numéricas, garantindo a exatidão dos resultados para análise dos dados (Malhotra, 2006). Como instrumento de coleta de dados, utilizou-se um questionário estruturado, de preenchimento automático, aplicado via web.

O questionário obteve 188 respostas válidas. Inicialmente, as dimensões compreendidas foram fundamentadas de acordo com a teoria de Jacobsen e Munar (2014), para o compartilhamento de experiências de viagens online e, conforme Parra-López et al (2011), para o planejamento de viagens. Nesse instrumento foi utilizada a escala Likert de sete pontos, contendo 15 questões (05 descritivas). Nesse artigo, as técnicas de análises utilizadas foram as correlações de Spearman, análise fatorial e Modelagem de equações estruturais com estimação do Partial Least Squares (PLS).

De acordo com Hair et al (2009, p. 33), a análise fatorial tem, por objetivo, "encontrar um meio de condensar a informação contida em várias variáveis originai em um conjunto menor de variáveis estatísticas com perda mínima de informação”. Para Hair et al (2009, p. 36), a 
modelagem de equações estruturais permite "separar relações para cada conjunto de variáveis dependente”. Essas técnicas foram utilizadas para alcançar os objetivos dessa investigação. A seguir serão apresentados os resultados e as discussões da pesquisa.

\section{Resultados e discussões}

De acordo com os dados da pesquisa, os internautas consideram que a mídia social os mantém atualizados, e tem o potencial de fazê-los conhecer diferentes destinos turísticos de seus interesses (4,46). Esse dado corrobora os dados apontados pela Trip Advisor Insights (2015), que indicam que, atualmente, as pessoas utilizam mais os seus celulares no planejamento e reserva de suas viagens, e consideram os seus smartphones, companheiros essenciais. O número de viajantes que realizaram suas reservas por meio dos aplicativos móveis dobrou, de 2014 para 2015, e a reserva da hospedagem se tornou mais habitual.

Outro resultado, a ser ressaltado na pesquisa, é que os respondentes afirmam que a mídia social permite uma economia dos recursos investidos em uma viagem $(4,01)$.

As redes sociais são hoje uma das principais ferramentas de promoção do turismo no Brasil e essenciais para divulgar e fomentar o setor pelo país (Brasil, MTur, 2015). De acordo com Seegers e Vermeulen (2009), muitos consumidores fazem consultas online antes de realizarem, e organizarem, as suas viagens. Esse dado tem relação com a carga fatorial "utilitário", explicado a seguir, e indica como o compartilhamento de informação apresenta um intuito mais "utilitário".

As menores médias, nos resultados descritivos, foram as variáveis "Gosto de compartilhar minhas impressões por meio da internet" $(3,32)$ e "eu compartilho informações das minhas viagens porque quero ser mais reconhecido pelas minhas experiências" $(2,37)$. A seguir, a tabela 1 apresenta os resultados acima discutidos. 
Tabela 1: Estatísticas descritivas

N Mín. Max. Média Desv. Pad.

A mídia social permite que eu me mantenha atualizado e conheça diferentes destinos turísticos de meu interesse.

A mídia social permite que eu economize os recursos investidos numa viagem.

$188 \quad 1,0 \quad 5,0 \quad 4,46 \quad 0,78$

(INVERSA) O tempo e o esforço pessoal que eu preciso para encontrar informações relacionadas a uma viagem, em mídia social, é excessivo e não vale a pena.

Eu confio nas contribuições dos turistas publicadas nas redes sociais.

Eu compartilho experiências de viagens nas redes sociais porque quero ajudar os outros.

$188 \quad 1,0 \quad 5,0 \quad 4,01 \quad 0,94$

Eu costumo compartilhar certas experiências de viagem para impedir que as pessoas utilizem produtos de má qualidade.

Quando eu compartilho as experiências de minhas viagens, eu contribuo para sites que são úteis para mim.

$188 \quad 1,0 \quad 5,0 \quad 3,93 \quad 1,17$

Quero manter conexões sociais e amizade quando compartilho experiências de viagens.

$188 \quad 1,0 \quad 5,0 \quad 3,84 \quad 0,80$

$188 \quad 1,0 \quad 5,0 \quad 3,44 \quad 1,31$

Gosto de compartilhar minhas impressões por meio da Internet.

$188 \quad 1,0 \quad 5,0 \quad 3,63 \quad 1,33$

$188 \quad 1,0 \quad 5,0 \quad 3,42 \quad 1,36$

Eu compartilho informações das minhas viagens porque quero ser mais reconhecido pelas minhas experiências.

Dias por semana que usa a internet.

Fez a última compra de viagem pela internet.

$188 \quad 1,0 \quad 5,0 \quad 3,43 \quad 1,40$

$188 \quad 1,0 \quad 5,0 \quad 3,32 \quad 1,30$

Escolaridade.

$188 \quad 1,0 \quad 5,0 \quad 2,37 \quad 1,29$

Idade.

$188 \quad 1,0 \quad 7,0 \quad 6,88 \quad 0,58$

Renda.

$188 \quad 1,0 \quad 2,0 \quad 1,29 \quad 0,46$

$188 \quad 1,0 \quad 5,0 \quad 3,70 \quad 1,15$

$188 \quad 1,0 \quad 4,0 \quad 2,41 \quad 1,06$

$188 \quad 1,0 \quad 5,0 \quad 3,78 \quad 0,94$

Fonte: Dados da pesquisa, 2016

De acordo com a correlação de Spearman (tabela 02), foi possível identificar uma concomitância entre as variáveis "Eu compartilho experiências de viagens nas redes sociais 
porque quero ajudar os outros" e "Eu costumo compartilhar certas experiências de viagem para impedir que as pessoas utilizem produtos de má qualidade" $(0,623)$, o que identifica uma coerência na escala. Foi detectada, também, uma correlação significante entre as variáveis acima mencionadas e a variável "Quando eu compartilho experiências de minhas viagens, eu contribuo para sites que são úteis para mim" (0,524 e 0,488, respectivamente).

As correlações, apontadas no presente estudo, corroboram a afirmação de Calder, Malthouse e Schaedel (2009) que defendem que as pessoas também utilizam a web para facilitar a sua interação com outras pessoas. Elas afirmam que a navegação por um site melhora a sua autoestima e que experimentam uma sensação de prazer intrínseco em utilizar o site por si só. Valorizam a entrada de novos usuários e se sentem motivadas com a entrada em uma comunidade virtual, pois, por meio dessa participação, é criada uma sociabilização que gera um envolvimento social interativo.

Outra, forte e significante, correlação identificada, foi entre as variáveis "Gosto de compartilhar minhas impressões por meio da Internet" e "Quero manter conexões sociais e amizade quando compartilho experiências de viagens" (0,578). Esse dado atesta o estudo de Brodie (2013) que defende que as principais consequências do engajamento incluem a lealdade, a satisfação, os direitos dos consumidores, a conexão emocional, a união, a confiança e o compromisso dos consumidores. 


\section{HOSPITALIDADE}

Tabela 2: Correlações de Spearman

\begin{tabular}{|c|c|c|c|c|c|c|c|c|c|c|c|c|c|c|c|}
\hline & & 1 & 2 & 3 & 4 & 5 & 6 & 7 & 8 & 9 & 10 & 11 & 12 & 13 & 14 \\
\hline 1 & $\begin{array}{l}\text { A mídia social permite que eu me mantenha atualizado e conheça } \\
\text { diferentes destinos turísticos de meu interesse. }\end{array}$ & 1,000 & & & & & & & & & & & & & \\
\hline 2 & $\begin{array}{l}\text { A mídia social permite que eu economize os recursos investidos numa } \\
\text { viagem. }\end{array}$ &, $366^{* *}$ & 1,000 & & & & & & & & & & & & \\
\hline 3 & $\begin{array}{l}\text { (INVERSA) O tempo e o esforço pessoal que eu preciso para encontrar } \\
\text { informações relacionadas a uma viagem, em mídia social, é excessivo e } \\
\text { não vale a pena. }\end{array}$ &, $336^{* *}$ &, $249^{* *}$ & 1,000 & & & & & & & & & & & \\
\hline 5 & $\begin{array}{l}\text { Eu compartilho experiências de viagens nas redes sociais porque quero } \\
\text { ajudar os outros. }\end{array}$ &, $279^{* *}$ &, $288^{* *}$ &, $162^{*}$ &, $330^{* *}$ & 1,000 & & & & & & & & & \\
\hline 6 & $\begin{array}{l}\text { Eu costumo compartilhar certas experiências de viagem para impedir que } \\
\text { as pessoas utilizem produtos de má qualidade. }\end{array}$ &, $147^{*}$ &, $154^{*}$ & ,101 &, $271^{* *}$ &, $623^{* *}$ & 1,000 & & & & & & & & \\
\hline 7 & $\begin{array}{l}\text { Quando eu compartilho experiências de minhas viagens, eu contribuo para } \\
\text { sites que são úteis para mim. }\end{array}$ &, $146^{*}$ &, $186^{*}$ &, $213^{* *}$ &, $246^{* *}$ &, $524^{* * *}$ &, $488^{* *}$ & 1,000 & & & & & & & \\
\hline 8 & $\begin{array}{l}\text { Quero manter conexões sociais e amizade quando compartilho experiências } \\
\text { de viagens. }\end{array}$ &, 115 &, $263^{* *}$ & ,029 &, $352^{* *}$ &, $430^{* * *}$ &, $366^{* *}$ &, $408^{* * *}$ & 1,000 & & & & & & \\
\hline 9 & Gosto de compartilhar minhas impressões por meio da Internet. &, $218^{* *}$ &, $294^{* *}$ &, $198^{* *}$ &, $368^{* *}$ &, $505^{* *}$ &, $401^{* *}$ &, $379^{* *}$ &, $578^{* *}$ & 1,000 & & & & & \\
\hline 10 & $\begin{array}{l}\text { Eu compartilho informações das minhas viagens porque quero ser mais } \\
\text { reconhecido pelas minhas experiências. }\end{array}$ &,- 004 &, 131 &,- 121 &, 141 &, $225^{* *}$ &, $167^{*}$ &, $184^{*}$ &, $431^{* *}$ &, $403^{* *}$ & 1,000 & & & & \\
\hline 11 & Dias por semana que usa a internet. & ,095 &, 104 &, 050 & ,044 & ,087 &, 021 & ,067 & ,013 &, 050 &,- 050 & 1,000 & & & \\
\hline 12 & Fez a última compra de viagem pela internet. & 042 &,$- 188^{* *}$ &,$- 162^{*}$ &,- 086 &,- 118 &,$- 150^{*}$ &,$- 239^{* *}$ &,- 112 &,- 101 & 076 &,- 087 & 1,000 & & \\
\hline 13 & Escolaridade. &, 083 & ,098 &, 136 & 044 &,- 113 &,- 063 & 019 &,- 071 &,- 058 &,- 049 &,- 005 &,- 111 & 1,000 & \\
\hline 14 & Idade. &,$- 318^{* *}$ &,$- 200^{* *}$ &,$- 249^{* *}$ & 024 &,- 010 & ,053 &,- 028 &,- 015 &,- 019 &,- 111 &,- 100 &, 141 &,- 111 & 1,000 \\
\hline 15 & Renda. & ,008 &, 043 &,- 084 &, $225^{* *}$ &, 114 &, 097 & , 126 & ,085 & ,018 &,- 028 &,- 021 &,- 052 &, $212^{* *}$ &, $254^{* *}$ \\
\hline
\end{tabular}

Fonte: Dados da pesquisa, 2016 


\section{Revista \\ ISSN 1807-975X}

A partir do resultado das cargas fatoriais, foram nomeados três fatores distintos, resultantes das variáveis do questionário (tabela 3). O primeiro fator, denominado utilitário, é representado por três questões Q1, Q2, Q3. Esse fator indica que o compartilhamento de informação apresenta um intuito mais utilitário. $\mathrm{O}$ segundo, nomeado por planejamento, é representado por quatro questões Q4, Q5, Q6, Q7. Esse fator indica que o indivíduo utiliza a mídia social para planejamento de suas viagens, para uma economia de recursos financeiros, para uma análise da contribuição dos demais turistas na mídia social e para conhecer diferentes destinos turísticos. O terceiro, nomeado por social, é representado por três questões Q8, Q9, Q10. Esse fator indica a capacidade de sociabilidade da mídia social, com foco no turismo, de formação de um vínculo, de socialização entre os indivíduos e do sentimento de participação na comunidade virtual. Estes resultados corroboram com a pesquisa de Munar e Jacobsen (2014), especialmente, na questão motivacional para o compartilhamento nas redes sociais.

Tabela 3: Análise Fatorial

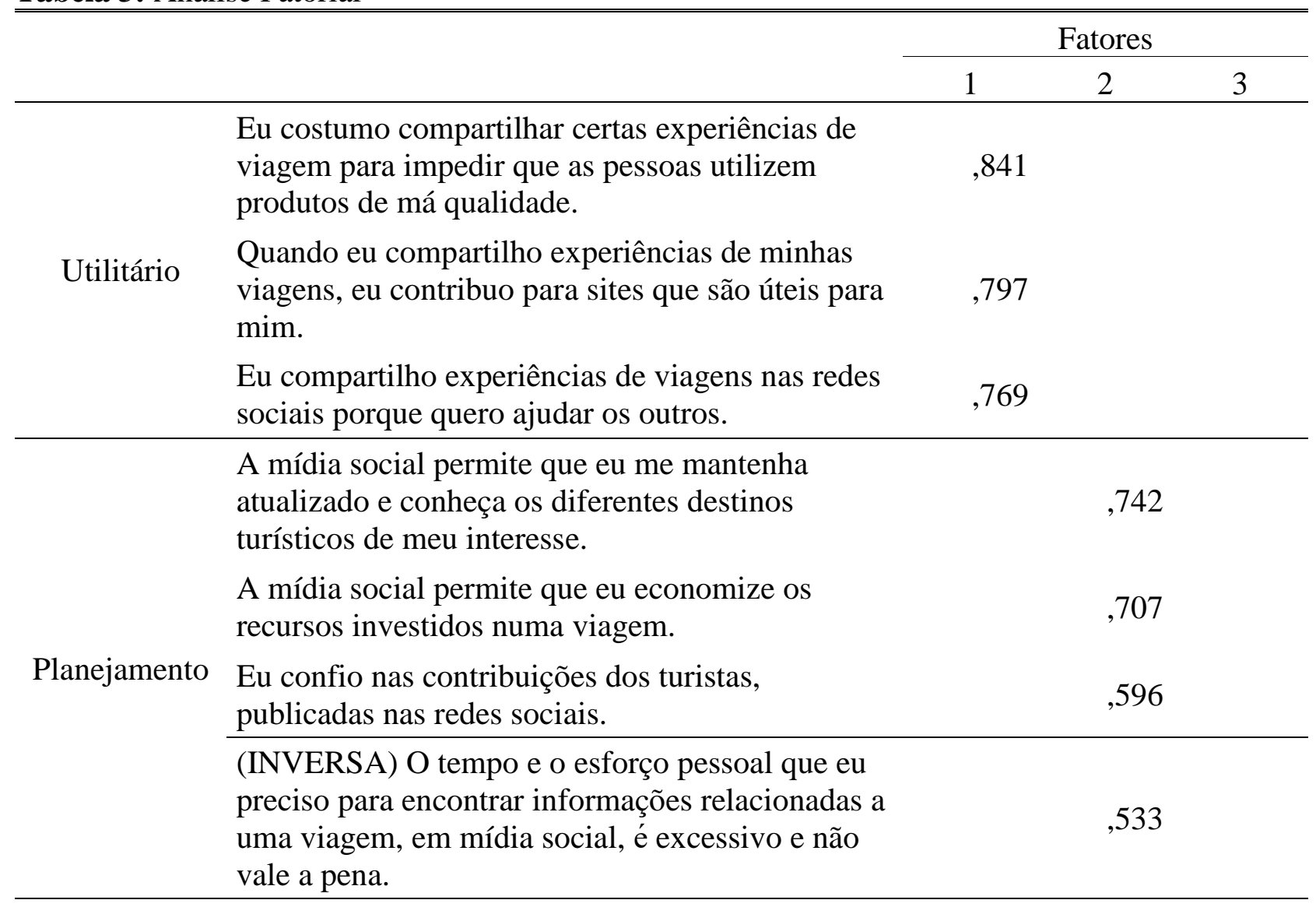


Eu compartilho informações das minhas viagens porque quero ser mais reconhecido pelas minhas experiências.

Social Quero manter conexões sociais e amizade quando compartilho experiências de viagens.

Gosto de compartilhar minhas impressões por meio da Internet.

Fonte: Dados da pesquisa, 2016

Ao relacionar com a carga fatorial social, resultante desse estudo, Jacobsen e Munar (2014) defendem que as experiências são pessoais e dependem de quanto o indivíduo percebe e reage à determinada vivência.

O compartilhamento de informações não só inclui os aspectos relacionados ao conhecimento, mas também a outros itens como: alojamento, clima, praias, atrações. Pode-se adicionar, a esses itens, as emoções, imaginações e fantasias que são registradas por meio de fotos, comentários e demais aspectos linguísticos digitais. (JACOBSEN e MUNAR, 2013). Wirtz (2013) complementa e menciona que o engajamento sugere que os membros estão interessados em ajudar outros membros, em participar de atividades conjuntas, em agirem por vontade que os liga à comunidade, de forma a aumentar o valor das marcas para si e para os outros.

Na carga fatorial, o "planejamento", indica que o indivíduo utiliza a mídia social: para o planejamento de sua viagem, para a economia de recursos financeiros, para a análise da contribuição de demais turistas na mídia social e para conhecer diferentes destinos turísticos.

De acordo com os testes de bootstraping, que roda testes para identificar se as relações são significantes entre os construtos do modelo e se indicam índices acima de 1,9 para todas as variáveis, pode-se identificar que todas as relações do modelo são significantes e, desse modo, faz sentido que sejam interpretadas (com rejeição à hipótese nula de que não haveria relação entre os construtos).

Conforme indicam as figuras 1 e 2, A variável, dependente no modelo, é a compra online, representada no questionário pela questão "Você fez a compra da viagem pela internet?" Quanto maior o compartilhamento social do indivíduo, maior a probabilidade de sua última compra ter 
sido realizada pela internet. Por outro lado, as relações entre "Planejamento e Compra" e "Compartilhamento Utilitário e Compra" obtiveram cargas negativas.

É possível observar que quanto maior for a tendência do usuário no compartilhamento utilitário, ou uso da internet para planejamento, menor será a tendência em comprar pela internet. Outra questão que foi constatada, é que, conforme os resultados, quanto maior for a tendência em utilizar a Internet para o planejamento, maior será o compartilhamento social e utilitário do usuário.

Figura 1: Cargas do PLS

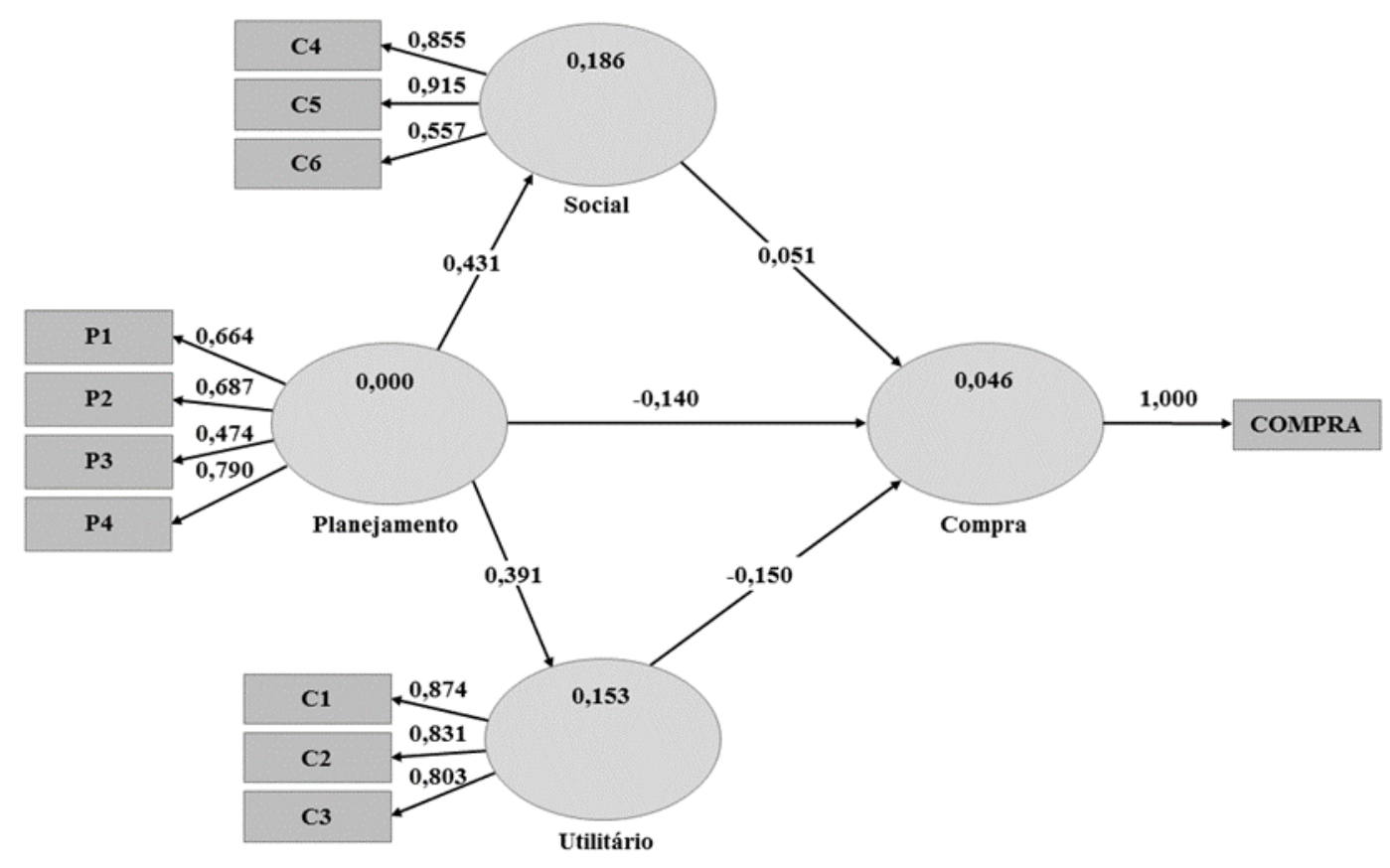

Fonte: Autores, 2016 
Figura 2: Significância do PLS

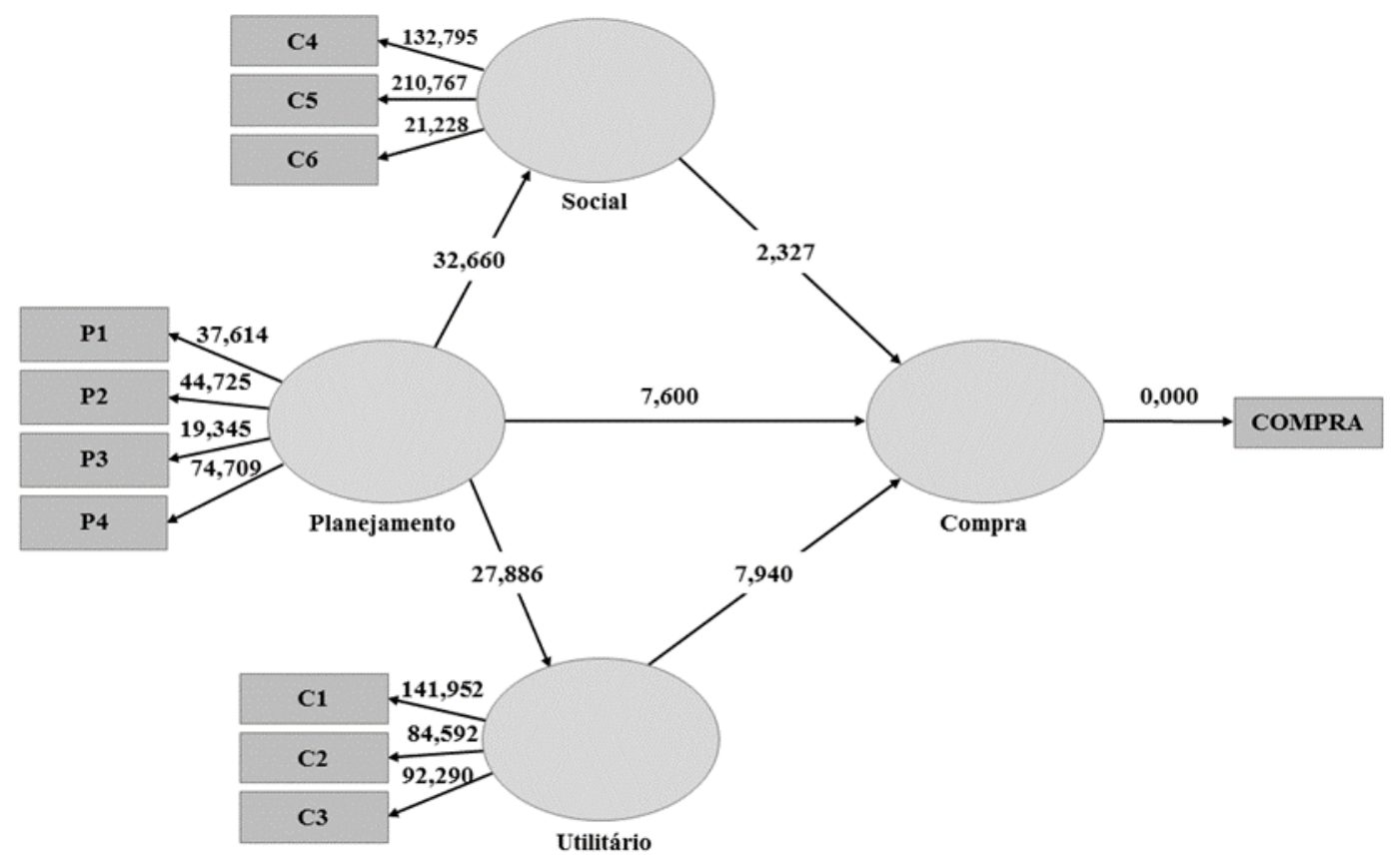

Fonte: Autores, 2016

\section{Considerações finais}

Atualmente, as redes sociais virtuais são uma das principais ferramentas de promoção do turismo no Brasil. As pessoas utilizam a web para facilitar seus contatos com as pessoas e, dessa maneira, o conceito de engajamento pressupõe o interesse dos membros em ajudar a outros membros e a participação em atividades conjuntas ligadas à comunidade.

Nesse sentido, o presente estudo teve por objetivo, analisar o engajamento, o planejamento e as experiências de viagens, compartilhados nas redes sociais virtuais.

A partir da análise de dados, foi possível identificar três tipos diferentes de cargas fatoriais: utilitário, planejamento e social. O primeiro, refere-se ao compartilhamento de informações com intuito mais utilitário. O segundo, reflete a utilização da mídia social com foco no planejamento de viagens, para a economia de recursos financeiros, a análise da contribuição de demais turistas e para conhecer diferentes destinos turísticos. O terceiro fator, indica a 
capacidade de sociabilidade da mídia social, com foco no turismo. Este fator está relacionado com a formação de um vínculo do usuário com a mídia social, da socialização entre os indivíduos e do sentimento de participação do usuário na comunidade virtual. Estes resultados são compatíveis com as investigações de Jacobsen e Munar (2014) e Parra-López et al (2011).

Os resultados expostos têm implicações diretas para as marcas, visto que, os usuários engajados fornecem mais interações e compartilhamento de informações e, sem dúvida, tornamse consumidores mais suscetíveis a compra. Afinal, quando o consumidor possui envolvimento, ele, automaticamente, dedica tempo e apresenta um compromisso com a organização. Portanto, os usuários utilizarão a mídia social virtual, para compartilhar e se informar, o que é considerado um reflexo da relação de engajamento criada.

As principais limitações do presente trabalho se referem à aplicação da investigação, limitada ao website. Dessa maneira, essa pesquisa pode ser considerada um insight sobre o engajamento, o planejamento e as experiências de viagens compartilhadas nas redes sociais e não permite generalizações, devido aos diferentes perfis de usuários. Para as próximas investigações, acerca do tema, sugere-se a realização de pesquisas qualitativas para analisar a relação entre o engajamento, o planejamento e as experiências de viagens compartilhados nas redes sociais.

\section{Referências}

ARSAL, I. The influence of electronic word of mouth in an online travel community on travel decisions: A case study. ProQuest, 2008.

BENNETT, M. M.; LAI, C. K. The impact of the internet on travel agencies in Taiwan. Tourism and Hospitality Research, v. 6, n. 1, p. 8-23, 2005.

BILGIHAN, A. et al. Consumer perception of knowledge-sharing in travel-related Online Social Networks. Tourism Management, v. 52, p. 287-296, 2016.

BOWDEN, J. The process of customer engagement: a conceptual framework. J. Marketing Theory Pract. v.17, n.1. p. 63-74, 2009.

BRODIE, R. et al. Consumer engagement in a virtual brand community: an exploratory analysis. J. Bus. Res., v.66, n.1. p. 105- 114. 2013. 
CALDER, J.B.; MALTHOUSE, C.; SCHAEDEL, U. An experimental study of the relationship between online engagement and advertising effectiveness. J. Int. Marketing, v.23, n.4, p. 321331. 2009.

CABIDDU, F.; DE CARLO, M.; PICCOLI, G. Social media affordances: Enabling customer engagement. Annals of Tourism Research, v. 48, p. 175-192, 2014.

CHAMUSCA, M.; CARVALHAL, M. Comunicação e marketing digitais: conceitos, práticas, métricas e inovações. Salvador: VNI, 2011.

GABRIEL, M., Marketing na era digital: conceitos, plataformas e estratégias. São Paulo: Novatec, 2010.

HAVEN, B. Marketing's new key metric: engagement. Forrest. 2007. Disponível em: https://www.adobe.com/enterprise/pdfs/marketing_new_key_metric_engagement.pdf. Acesso em: 10 jun. 2016.

HAIR, J. F.; BLACK, W. C.; BABIN, B. J.; ANDERSON, R. E.; TATHAM, R. L.; Análise multivariada de dados. Porto Alegre: bookman, 2009.

HAYS, S.; PAGE, S. J.; BUHALIS, D. Social media as a destination marketing tool: its use by national tourism organizations. Current issues in tourism, v. 16, n. 3 p. $211-239,2012$

HOLLEBEEK, L. D.; GLYNN, M. S.; BRODIE, R. J. Consumer brand engagement in social media: Conceptualization, scale development and validation. Journal of interactive marketing, v. 28, n. 2, p. 149-165, 2014.

JACOBSEN, J.K.S.; MUNAR, A.M., Motivations for sharing tourism experiences through social media. Tourism management. P. 46-54. 2014

KANG, M.; SCHUETT, M. A. Determinants of sharing travel experiences in social media. Journal of Travel \& Tourism Marketing, v. 30, n. 1-2, p. 93-107, 2013

KUMAR, V. et al. Undervalued or overvalued customers: capturing total customer engagement value. Journal of Service Research, v. 13, n. 3, p. 297-310, 2010.

LEUNG, D. et al. Social media in tourism and hospitality: A literature review. Journal of Travel \& Tourism Marketing, v. 30, n. 1-2, p. 3-22, 2013.

MALHOTRA, N. Pesquisa de marketing: uma orientação aplicada. Porto Alegre: Bookman, 2006.

MINISTÉRIO DO TURISMO. Redes sociais ampliam a comunicação do Turismo. Brasília, 2015. 
para viajar. Brasília, 2015.

Brasileiros estão entre os que mais usam smartphone

visitantes. Brasília, 2015. Redes sociais ajudam a divulgar destinos e atrair

IP, C.; LEE, H.; LAW, R. Profiling the users of travel websites for planning and online experience sharing. Journal of Hospitality \& Tourism Research, v. 36, n. 3, p. 418-426, 2012.

PARRA-LÓPEZ, E. et al; Intentions to use social media in organizing and taking vacation trip. J. Computers in Human Behavior. p. 640-654. 2011.

SEEGERS, D.; VERMEULEN, I.E.; Tried and tested: The impact of online hotel reviews on consumer consideration. Tourism Management. p.123-127. 2009.

SO, K. K. F. et al. The role of customer engagement in building consumer loyalty to tourism brands. Journal of Travel Research, v. 55, n. 1, p. 64-78, 2016.

TRIP ADVISOR INSIGHTS. Você está atingindo os viajantes conectados lucrativos? 2015. . Aumente as reservas feitas em dispositivos móveis com estas informações do TripBarometer. 2015.

VIVEK, S. D. et al. A generalized multidimensional scale for measuring customer engagement. Journal of Marketing Theory and Practice, v. 22, n. 4, p. 401-420, 2014.

XIANG, Z.; GRETZEL, U. Role of social media in online travel information search. Tourism Management, v. 31, p. 179-188, 2010.

WANG, Y.; FESENMAIER, D. R. Towards understanding members' general participation in and active contribution to an online travel community. Tourism management, v. 25, n. 6, p. 709-722, 2004.

WANG, X. et al. A Moderated Mediation Model of Sharing Travel Experience on Social Media: Motivations and Face Orientations in Chinese Culture. Journal of China Tourism Research, p. 1-23, 2016.

WIRTZ, J. Managing brands and customer engagement in online brand communities. Int. J. Serv. Ind. Manag., v.24, n.3, p. 223-244. 2013.

YOO, K. H.; GRETZEL, U. Use and Creation of Social Media by. Social media in travel, tourism and hospitality: Theory, practice and cases, p. 189, 2016.

ZENG, B.; GERRITSEN, R., What do we know about social media in tourism? A review. Tourism Management Perspectives, v. 10. p. 27-36. 2014. 
ZUCCO, F. D.; BAHR, G.; LIMBERGER, P. F. Engajamento, planejamento e experiências de viagem compartilhadas. Revista Hospitalidade. São Paulo, volume 1, n.01, p. 01-19, agosto de 2017.

Recebido em: 05/04/2017

Revisto em: 13/06//2017

Aprovado em: 31/08/2017 